\title{
Epidemiologic Data, Tumor Size, Histologic Tumor Type and Grade, Pathologic Staging and Follow Up in Cancers of the Ampullary Region and Head of Pancreas in 311 Whipple Resection Specimens of Pakistani Patients
}

\author{
Zubair Ahmad, Nasir Ud Din*, Khurram Minhas, Sarosh Moeen, Arsalan Ahmed
}

\begin{abstract}
Aim: To report the histologic findings on Whipple resection specimens and thus determine the extent and spread of carcinomas of ampullary region and head of pancreas in our population. Setting: Section of Histopathology, Department of Pathology, Aga Khan University Hospital (AKUH), Karachi, Pakistan. Materials and Methods: A case series of 311 consecutive Whipple resection specimens received between January 1,2003 and December 31, 2014. Specimens processed for histologic sections and representative sections submitted and histologically examined as per established and standard protocols. All relevant tumor parameters including histologic type, histologic grade, pathologic $T$ and $N$ stage and tumor size were assessed. Epidemiologic data were also recorded. All findings were analysed using SPSS 19.0 software. Results: Ampullary (periampullary) carcinomas were much more common than carcinomas of the head of the pancreas, especially in males, with an average age of 53 years. Mean tumor size was $2.5 \mathrm{cms}$, over $54 \%$ were well differentiated. A large majority were pT2 or pT3 and No. Carcinomas of pancreatic head were also more common in males, mean age was 55 years, mean tumor size was $3.5 \mathrm{cms}$, and over $65 \%$ were moderately differentiated. The majority were T2 or T3 and pN1. Prognostically, significant statistical correlation was seen with tumor grade and pathologic $T$ and $N$ stage (p values statistically significant). However, tumor size was not statistically significant. Conclusions: Ampullary carcinomas are more common compared to pancreatic carcinomas. Majority of ampullary carcinomas were well differentiated while majority of pancreatic carcinomas were moderately differentiated. Large majority of both types of cases were pT2 or T3. Histologic tumor grade and pathologic $\mathrm{T}$ and $\mathrm{N}$ stage are significantly related to prognosis in Pakistani patients with ampullary and pancreatic cancers.
\end{abstract}

Keywords: Whipple resection - carcinoma of ampullary region - carcinoma of head of pancreas - tumor grade

Asian Pac J Cancer Prev, 16 (17), 7541-7546

\section{Introduction}

Pancreaticoduodenectomy (Whipple resection), which was first performed by Whipple in 1935 (Whipple et al.,1935) for carcinomas of ampulla/periampullary region, has over the years expanded to include carcinomas of head of pancreas, duodenum and common bile duct and is a safe and effective procedure for the treatment of the above malignancies (Longmire and Traverso, 1981). It is also often performed in those patients with chronic pancreatitis who have severe symptoms which are not responding to medical therapy. Conversely, some Whipple resections performed for a suspicious malignancy reveal chronic pancreatitis on histological examination (Abraham et al., 2003; Kavanagh et al., 2008). With better surgical skills and improved perioperative care, operative mortality rates for pancreatic carcinoma have greatly declined while 5- year survival rates have improved
(Sohn et al., 2000; Morris-Stiff et al., 2009). Even in poor, developing countries, refinements in surgical techniques have resulted in better perioperative outcomes following pancreaticoduodenectomy (Shrikhande et al., 2012). In patients undergoing Whipple resection for chronic pancreatitis also, the quality of life has been shown to improve greatly (Sohn et al., 2000). The Whipple resection specimen includes the duodenum, head of pancreas, distal bile duct, and sometimes distal stomach. The following margins should be recognized and submitted for histopathologic examination when a specimen is received: common bile duct, pancreatic tissue, peripancreatic soft tissue and distal duodenal resection margins (Kayahara and Ohta, 2010). The pathological examination of Whipple resection specimens is important in evaluating multiple parameters which are prognostically important. These include tumor site and size, tumor extension, histologic type, tumor grade, vascular and /or perineural invasion, 
status of surgical margins, lymph node status, tumor stage etc (Martin et al.,1990; Bouvet et al., 2000; Lazaryan et al., 2008; Badger et al., 2010). Therefore, the pathologist on receiving a whipple resection must report all the above mentioned parameters in order to provide adequate information to the clinician.

The aim of the present study was to present the results of pathologic findings in Whipple resection specimens in the largest center for histopathology in the country. These results, on a large number of Whipple resections, will provide valuable information about the extent and spread of ampullary (periampullary) carcinomas, carcinomas of head of pancreas, common bile duct, duodenum etc in our population.

\section{Materials and Methods}

A case series of 311 consecutive Whipple resection specimens received in the Section of Histopathology, Aga Khan University Hospital between January 1, 2003 and December 31, 2014. All specimens were fixed in $10 \%$ buffered formalin, allowed to stay overnight, and then grossed with representative sections submitted as per established protocols (Rosai, 2004). Sections were routinely processed under standard conditions for paraffin embedding and stained with Hematoxylin and Eosin. Reporting was done using a standard format for reporting all relevant tumor parameters (Amin and Washington, 2010; Compton, 2003). All the relevant data was recorded and was analysed using a commercially available SPSS 19.0 software package. Mean+/- SD, frequencies and percentages were calculated for the following variables: patient age, gender,survival in months, tumor size, histologic tumor type, tumor grade, pathologic stage (pT), lymph node status $(\mathrm{pN})$, and status of surgical margins. Patients were divided into 4 survival groups i.e. less than 10 months, 11 to 40 months, 41 to 80 months and greater than 80 months. Fisher exact test or chi square tests were used to calculate $p$-values regarding association of survival with tumor grade, pathologic stage, lymph node status and tumor size. P-value equal to or less than 0.05 was considered significant.

\section{Results}

A total of 311 Whipple resection specimens were included in the study. These included 196 specimens $(63 \%)$ from the ampullary and periampullary region and the duodenum; and 115 (37\%) from the head of pancreas and common bile duct.

The histological typing of group 1 is presented in Figure 1. Out of these 196 cases, 128(65.3\%) occurred in males, and $68(34.7 \%)$ in females. Male to female ratio was 1.9:1. Clinicopathological characteristics are presented in Table 1. Out of the 115 cases in the second group, 15 (13\%) turned out to be non-neoplastic showing changes of chronic pancreatitis. Histological typing of tumors in group 2 is shown in Figure 2. Of the 92 cases of adenocarcinomas, $81(88 \%)$ occurred in the head of pancreas, while $11(12 \%)$ were in the common bile duct. Of these 92 patients, $55(59.7 \%)$ were males and 37
(40.2\%) were females.. Male to female ratio was 1.5:1. Average number of lymph nodes recovered from each case was 11.7. Average number of positive nodes per case was 4.3. A total of 10 cases in the study had positive margins. These included 6 cases of pancreatic carcinoma, 2 cases of ampullary carcinoma, and 2 cases of bile duct carcinoma. Out of these 10 cases, 7 (including 5 of 6 pancreatic carcinoma) had a positive pancreatic margin, while 3 had a positive common bile duct margin.

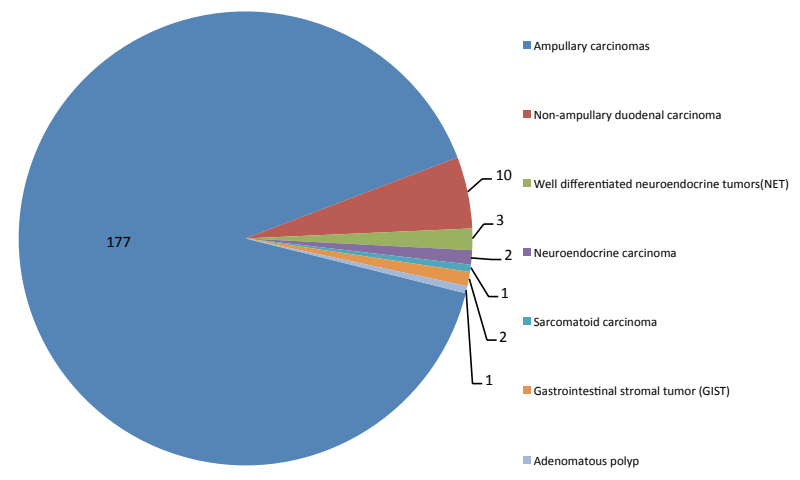

Figure 1. Breakup of Tumors of Ampullary Region and Duodenum $(\mathbf{n}=196)$

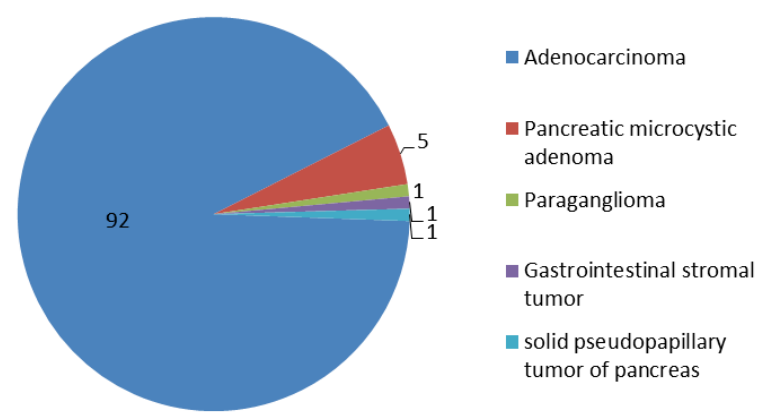

Figure 2. Tumors of Pancreatic Head and Common Bile Ducts $(\mathbf{n}=\mathbf{1 0 0})$

Table 1. Clinicopathological Characteristics of Ampullary/periampullary and Duodenal Carcinomas (Group 1)

\begin{tabular}{lrr}
\hline $\begin{array}{l}\text { Clinico- } \\
\text { pathological features }\end{array}$ & $\begin{array}{r}\text { Ampullary/periampullary } \\
(\mathrm{n}=177)\end{array}$ & $\begin{array}{r}\text { Duodenal } \\
(\mathrm{n}=10)\end{array}$ \\
\hline \multicolumn{2}{l}{ Age (years) (mean 53, range 21-79) } & \\
Tumor size (cm) (mean 2.5, range 1-11.7 cm) & \\
pT stage & & \\
T1 & $72(9.6 \%)$ & 0 \\
T2 & $86(40.7 \%)$ & 3 \\
T3 & $2(1.1 \%)$ & 3 \\
T4 & & 4 \\
Histological grade & $96(54.2 \%)$ & 2 \\
Well differentiated & $75(42.4 \%)$ & 6 \\
Moderately differentiated & $6(3.4 \%)$ & 2 \\
Poorly differentiated & & \\
Lymph node status & $101(57.1 \%)$ & 2 \\
Absent (N0) & & \\
Present & $68(38.4 \%)$ & 5 \\
- N1 & & - \\
- N2 & $8(4.5 \%)$ & 3 \\
Not available & & 0 \\
\hline
\end{tabular}


Follow up was available in only 74 out of 296 cases with carcinoma (15 out of 311 patients had chronic pancreatitis). Out of these 74 cases, 31 patients died of disease, while 43 were alive. Of the 31 patients who died, $10(32 \%)$ were grade $1,18(58 \%)$ were grade 2 , and $3(10 \%)$ were grade 3 . Most grade 2 and all grade 3 patients died within 1 to 2 years. The $\mathrm{p}$ value was significant $(<0.017)$.

Out of these, 4(13\%) were T1, $15(48 \%)$ were T2, 11 (35\%) were T3 and 1 was T4(3\%). Most patients who died were T2 or T3 and most patients died within 1 to 2 years

Table 2. Clinicopathological Characteristics of Tumors of Pancreatic Head and Common Bile Duct (CBD), Group 2

\begin{tabular}{|c|c|c|}
\hline $\begin{array}{l}\text { Clinico- } \\
\text { pathological features }\end{array}$ & $\begin{array}{r}\text { Pancreatic head } \\
\qquad(\mathrm{n}=81)\end{array}$ & $\begin{array}{r}\text { CBD } \\
(\mathrm{n}=11)\end{array}$ \\
\hline \multicolumn{3}{|c|}{ Age (years) (mean 55, range 20-75) } \\
\hline \multicolumn{3}{|c|}{ Tumor size $(\mathrm{cm})$ (mean 3.5 , range $1.5-11 \mathrm{~cm})$} \\
\hline \multicolumn{3}{|c|}{ pT stage } \\
\hline $\mathrm{T} 1$ & $8(9.9 \%)$ & 2 \\
\hline $\mathrm{T} 2$ & $36(44.4 \%)$ & 4 \\
\hline T3 & $35(43.2 \%)$ & 5 \\
\hline $\mathrm{T} 4$ & $2(2.5 \%)$ & 0 \\
\hline \multicolumn{3}{|l|}{ Histological grade* } \\
\hline Well differentiated & $22(29 \%)$ & 3 \\
\hline Moderately differentiated & $51(67 \%)$ & 8 \\
\hline Poorly differentiated & $3(4 \%)$ & - \\
\hline \multicolumn{3}{|l|}{ Lymph node status } \\
\hline Absent (N0) & $34(42 \%)$ & 8 \\
\hline \multicolumn{3}{|l|}{ Present } \\
\hline$-\mathrm{N} 1$ & $42(51.8 \%)$ & 3 \\
\hline Not available & $5(6.2 \%)$ & 0 \\
\hline
\end{tabular}

(Table 4). The p-value was significant $(<0.004)$.

Of the 31 patients who died, $18(58 \%)$ were N0 and $13(42 \%)$ were N1. Most patients who died, whether N0 or $\mathrm{N} 1$ died within 1 to 2 years. The p-value was significant $(<0.006)$.

Of the 31 patients who died, tumor size was less than $3 \mathrm{cms}$ in $22(71 \%)$ and $3 \mathrm{cms}$ or greater in $9(29 \%)$ patients. There was no significant difference in time duration between diagnosis and death in the two groups of patients. The p-value was not significant $(0.625)$.

Table 5. Comparison between Patients Based on Follow Up

\begin{tabular}{lrr}
\hline Clinico-pathological features & $\begin{array}{c}\text { Died of Disease } \\
(\mathrm{n}=31)\end{array}$ & \multicolumn{1}{c}{$\begin{array}{c}\text { Alive } \\
(\mathrm{n}=43)\end{array}$} \\
\hline $\begin{array}{l}\text { Tumor size (cm) } \\
\quad 3 \mathrm{~cm}\end{array}$ & $22(71 \%)$ & $30(70 \%)$ \\
$\quad>3 \mathrm{~cm}$ & $9(29 \%)$ & $3(30 \%)$ \\
pT stage & $4(13 \%)$ & $4(9 \%)$ \\
T1 & $15(48 \%)$ & $17(40 \%)$ \\
T2 & $11(35 \%)$ & $21(49 \%)$ \\
T3 & $1(3 \%)$ & $1(2 \%)$ \\
T4 & $10(32 \%)$ & $12(30 \%)$ \\
Histological grade* & $18(58 \%)$ & $29(65 \%)$ \\
$\quad$ Well differentiated & $3(10 \%)$ & $2(5 \%)$ \\
Moderately differentiated & \\
Poorly differentiated & & \\
Lymph node status & $18(58 \%)$ & $26(60 \%)$ \\
Absent (N0) & & \\
Present & $13(42 \%)$ & $17(40 \%)$ \\
$\quad$ N1 & & \\
* Histological grading of only conventional adenocarcinoma is included (n=76)
\end{tabular}

Table 3. Data of Patients who Died of Disease $(n=31)$

\begin{tabular}{|c|c|c|c|c|c|c|}
\hline Parameters & $\begin{array}{r}\text { Ampullary/ } \\
\text { periampullary } \\
(n=19)\end{array}$ & $\begin{array}{r}\text { Survival } \\
\text { (months) }\end{array}$ & $\begin{array}{r}\text { Pancreatic } \\
\text { head } \\
(n=10)\end{array}$ & $\begin{array}{r}\text { Survival } \\
\text { (months) }\end{array}$ & $\begin{array}{r}\mathrm{CBD} ; \mathrm{n}=1 \\
\text { (survival in } \\
\text { months) }\end{array}$ & $\begin{array}{r}\text { Duodenum; } \mathrm{n}=1 \\
\text { (survival in } \\
\text { months) }\end{array}$ \\
\hline Size $(\mathrm{cm})$ & $1-6($ mean 2.2$)$ & & & & & \\
\hline \multicolumn{7}{|c|}{ Pathological stage } \\
\hline pT1N0 & 2 & 70,1 & - & - & - & \\
\hline $\mathrm{pT} 2 \mathrm{~N} 0$ & 4 & $23,27,22,8$ & 3 & $10,21,8$ & $1(22)$ & $1(2)$ \\
\hline pT3N0 & 4 & $57,5,14,4$ & 2 & 4,7 & - & \\
\hline pT4N0 & 1 & 11 & - & & - & \\
\hline pT1N1 & 2 & 25,18 & - & & - & \\
\hline pT2N1 & 3 & $30,5,2$ & 3 & $12,12,9$ & - & \\
\hline pT3N1 & 3 & $14,25,9$ & 2 & 13,9 & - & \\
\hline pT4N1 & - & & - & & & \\
\hline
\end{tabular}

Table 4. Data of Patients who are Alive at Follow up $(n=43)$

\begin{tabular}{|c|c|c|c|c|c|}
\hline Parameters & $\begin{array}{r}\text { Ampullary/ } \\
\text { periampullary } \\
(\mathrm{n}=31)\end{array}$ & $\begin{array}{r}\text { Survival } \\
\text { (months) }\end{array}$ & $\begin{array}{r}\text { Pancreatic head } \\
\qquad(\mathrm{n}=10)\end{array}$ & $\begin{array}{l}\text { Survival } \\
\text { (months) }\end{array}$ & $\begin{array}{r}\text { Duodenum; } \mathrm{n}=2 \\
\text { (survival in months) }\end{array}$ \\
\hline$\overline{\text { Size }(\mathrm{cm})}$ & $0.8-6($ mean 2.5$)$ & & & & \\
\hline \multicolumn{6}{|c|}{ Pathological stage } \\
\hline pT1N0 & 1 & 47 & - & - & \\
\hline pT2NO & 11 & $26,25,21,19,11,11,9,66,56,53,50$ & 2 & 105,32 & \\
\hline pT3N0 & 9 & $27,13,12,147,108,66,53,41,36$ & 3 & $26,13,118$ & \\
\hline pT4N0 & - & - & - & - & \\
\hline pT1N1 & 2 & 16 & 1 & 25 & \\
\hline pT2N1 & 1 & 50 & 3 & $12,45,36$ & \\
\hline pT3N1 & 7 & $25,20,27,54,33,41,34$ & 1 & 33 & $1(25)$ \\
\hline pT4N1 & - & - & - & - & $1(96)$ \\
\hline
\end{tabular}


Of the 43 patients who were alive on follow up 12 (30\%) were grade $1,29(65 \%)$ were grade 2 , and 2 patients (5\%) were grade 3.

Of the 43 patients who were alive, $4(9.5 \%)$ are $\mathrm{T} 1$, $17(40 \%)$ were T2, $21(49 \%)$ were T3 and 1 was a T4 lesion $(2 \%)$.

Of the 43 patients who were alive, $26(60 \%)$ were N0, and $17(40 \%)$ were N1.

Of the 43 patients who were alive at follow up, tumor size was less than $3 \mathrm{cms}$ in $30(70 \%)$ and $3 \mathrm{cms}$ or greater in $13(309 \%)$ patients.

\section{Discussion}

Although there is a previous study from Pakistan (Qureshi et al., 2011), the current study is the largest study on Whipple resection specimens from Pakistan with 311 cases (previous study looked at 65 cases). A study from Iran looked at 51 cases (Foroughi et al., 2012).

We divided our cases into two large groups. The first group comprised of ampullary/periampullary carcinomas (including carcinomas located in other areas of duodenum), while the second group comprised of lesions of head of pancreas and extrahepatic ducts. Of the latter group, 15 out of 115 cases $(13 \%)$ did not reveal any malignancy on histopathological examination. Instead changes of chronic pancreatitis were seen. Whipple resection is now quite commonly performed in patients with chronic pancreatitis with severe symptoms intractable to medical therapy (Sohn et al., 2000; Abraham et al., 2003). However, in all 15 of our cases which revealed chronic pancreatitis, the Whipple resection had been performed on suspicion of malignancy. Various studies have shown that a variable percentage of Whipple resections done with suspicion of pancreatic carcinoma turn out to be benign on histologic examination. The frequency of benign disease on Whipple specimens has ranged in different studies from 7 to $15 \%$ (Abraham et al., 2003; Kavanagh et al., 2008; van Roest et al., 2008; Foroughi et al., 2012). Our results are somewhat on the higher side with almost $13 \%$ cases showing benign disease.

The prognosis of ampullary carcinomas is significantly better than that of pancreatic or bile duct carcinomas. In our study, the majority of ampullary carcinomas occurred in males $(65 \%)$. Various studies have also shown that these carcinomas are more common in males (Yeo et al., 1997; Qureshi et al., 2011; Foroughi et al., 2012; Adsay et al., 2013). Various studies have shown that ampullary and pancreatic carcinomas are more common in males and peak age is in the fifth and sixth decades. In a recent study (Adsay et al., 2013), almost $60 \%$ of ampullary region carcinomas occurred in males and $40 \%$ in females, and mean age for these carcinomas was 65 years. In the same study, $38 \%$ of pancreatic adenocarcinomas occurred in males and $62 \%$ in females. Mean age for pancreatic adenocarcinoma was 64 years. Two recent studies reported an overall male predominance in ampullary and pancreatic adenocarcinomas. Males comprised $60 \%$ and $72.5 \%$ respectively in these studies. In these studies, mean age was 50.2 and 57 years for ampullary and pancreatic adenocarcinomas respectively (Qureshi et al.,
2011; Foroughi et al., 2012). In our study, almost $65 \%$ of ampullary and $60 \%$ of pancreatic adenocarcinomas occurred in males. In our study, the mean age for ampullary and pancreatic adenocarcinomas was 53 and 55 years respectively.

According to a recent study, mean tumor size was $2.6 \mathrm{cms}$ for ampullary and $3.6 \mathrm{cms}$ for pancreatic adenocarcinomas (Adsay et al., 2013), while two other recent studies reported an overall mean tumor size of $2.5 \mathrm{cms}$ and $2.8 \mathrm{cms}$ respectively for both ampullary and pancreatic adenocarcinomas (Qureshi et al., 2011; Foroughi et al., 2012). In our study, mean tumor size was $2.5 \mathrm{cms}$ for ampullary and $3.5 \mathrm{cms}$ for pancreatic adenocarcinomas.

Most of the ampullary and pancreatic adenocarcinomas in our study were well to moderately differentiated, and poorly differentiated carcinomas were very rare comprising 3.4 and $3.2 \%$ respectively of the two groups of tumors. It has been suggested that ampullary carcinomas are often poorly differentiated but this was not true for our cases. In a recent local study (Qureshi et al., 2011), well, moderately and poorly differentiated adenocarcinomas (ampullary and pancreatic adenocarcinomas combined) comprised $27.6 \%, 58.5 \%$ and $13.9 \%$ respectively. In another recent study (Foroughi et al., 2012), 59.1\% tumors were well differentiated, while $4.3 \%$ were poorly differentiated (Ampullary and pancreatic adenocarcinomas combined). However, in a study by Sohn et al. (2000), poorly differentiated pancreatic adenocarcinomas accounted for $36 \%$. As shown in Table 2, the large majority (almost $90 \%$ ) of ampullary carcinomas in our study were T2 (tumor invading duodenal wall), or T3 (tumor invading pancreas). Similarly as shown in Table 3, the large majority $(87.6 \%)$ of pancreatic carcinomas were also either T2 (tumor limited to the pancreas but more than 2 $\mathrm{cms}$ in greatest dimension) or T3 (tumor extending beyond the pancreas but not involving the celiac axis or superior mesenteric artery). As shown in Table 2,57\% of ampullary carcinomas in our series were N0 while over $38 \%$ were N1. However, a recent study has shown that increased number of positive nodes in ampullary carcinomas is associated with a worse prognosis and the authors have recommended that ampullary carcinomas should be categorized as N0 (no lymph node metastasis), N1 (1 to 2 positive nodes) and N2 ( 3 or more positive nodes) (Kang et al., 2014). As shown in Table 3 , almost $52 \%$ of pancreatic adenocarcinomas in our study were N1, while $42 \%$ were N0.

The prognosis of ampullary carcinomas is much better than that of pancreatic or cholangiocarcinoma, but depends mainly on stage (Sessa et al., 2007). Studies have shown that stage I carcinomas may have 5 year survival rate as high as $85 \%$ (Yamaguchi and Enjoji, 1987). The prognosis is especially good if lymph node metastases are not present (Sohn et al, 2000). Unfortunately, very few cases in our study $(<10 \%)$ were T1; however $57 \%$ were N0.

Cigarette smoking, diabetes mellitus and cholelithiasis are important risk factors for pancreatic adenocarcinoma (Hadizadeh et al., 2014). The incidence of pancreatic adenocarcinoma is steadily increasing in developing countries although incidence rates are still much lower than those in developed countries (Zahir et al., 2013). 
Pancreatic adenocarcinoma has a very poor prognosis, and studies show that over $90 \%$ patients die in less than a year after diagnosis (Gudjonsson, 1987). Studies have shown that 5 year survival rates are only around $15 \%$ even when the tumor is limited to the pancreas (Tepper et al., 1976). Tumor stage remains the most important factor prognostically (Allema et al., 1995). However, tumors less than $4.5 \mathrm{cms}$ in diameter show the largest survival rates (Nix et al., 1991). A large study of 616 resected adenocarcinomas of pancreas showed that negative tumor margins (complete resection), tumor size (less than $3 \mathrm{~cm}$ ) and well to moderate tumor differentiation are important prognostic indicators (Sohn et al., 2000). The average tumor size of pancreatic carcinomas in our study was 3.5 $\mathrm{cm}$. However, the large majority (over 96\%) of pancreatic carcinomas in our series were well to moderately differentiated and resection margins were negative in 75 out of 81 cases $(92.6 \%)$. Unfortunately, most cases in our series were T2 and T3 and majority were positive for nodal metastases. Most patients with both ampullary and pancreatic adenocarcinomas in two recent studies had T2 or T3 disease. Similarly, nodal metastases were present in almost $48 \%$ and 36\% cases (Qureshi et al., 2011; Foroughi et al., 2012). Adsay et al. (2013) dealt with ampullary and pancreatic carcinomas separately. They showed a greater percentage of stage I and II tumors than stage III and IV for ampullary carcinomas, and reported lymph node metastases in $39 \%$ cases of ampullary and $73 \%$ cases of pancreatic adenocarcinomas.

Of the 11 cases of common bile duct carcinomas in our study, 5(45.5\%) were T3 and 8(72.7\%) were N0. A recent study showed that biliary tract carcinomas generally have a poor prognosis and that gallbladder localization, perineural invasion, liver invasion, lack of lymph node dissection and lack of adjuvant chemoradiation following surgical resection were poor prognostic factors for survival (Unal et al., 2014)

Follow up was unfortunately available in only 82 out of 296 patients in our series with carcinoma ( 15 out of 311 patients turned out to have chronic pancreatitis), the main reason being that we receive cases from the whole country and the data encompassed a long period of 12 years going back to 2003. However, as shown in the results, follow up from the dead and alive patients indicated that histologic tumor grade, pathologic stage, lymph node status were important prognostic determinants with statistically significant p-values. However, in our study, tumor size was not statistically significant (see results). A number of studies have also shown that tumor grade, stage, lymph node status and tumor size are important prognostic indicators which are closely and significantly associated with survival in these patients (Allema et al., 1995; Castro et al., 2004; Lazaryan et al., 2008; Morris-Stiff et al., 2009; Kayahara and Ohta, 2010; Qureshi et al., 2011; de Thomas and Ahmad, 2012). However, like in our study, tumor size was not seen to be significant in a study from Cleveland Clinic (Lazaryan et al., 2008). A recent study showed that socio-economic and racial factors also impact on pancreas cancer outcome (Cheung, 2013). Similarly, a study from Australia also showed higher case fatality in older patients and in patients from lower socio-economic groups (Luke et al., 2009).

We hope that this large study will provide valuable information about the extent and spread of ampullary, pancreatic head, duodenal and common bile duct cancers in the Pakistani population.

\section{References}

Abraham SC, Wilentz RE, Yeo CJ, et al (2003). Pancreaticoduodenectomy (Whipple Resections) in patients without malignancy: are they all 'chronic pancreatitis'? Am J Surg Pathol, 27, 110-20.

Adsay V, Ohike N, Tajiri T, et al (2013). Ampullary region carcinomas: definition and site specific classification with delineation of four clinicopathologically and prognostically distinct subsets in an analysis of 249 cases. Am J Surg Pathol, 36, $1592-608$.

Allema JH, Reinders ME, van Gulik TM, et al (1995). Prognostic factors for survival after pancreaticoduodenectomy for patients with carcinoma of the pancreatic head region. Cancer, 75, 2069-76.

Amin MB, Washington K eds (2010). Reporting on Cancer Specimens Case Summaries and Background Documentation 2009, 2010. Northfield, IL, College Am Pathol.

Badger SA, Brant JL, Jones C, et al (2010). The role of surgery for pancreatic cancer: a 12-year review of patient outcome. Ulster Med J, 79, 70-5.

Bouvet M, Gamagami RA, Glipin EA, et al (2000). Factors influencing survival after resection for periampullary neoplasms. Am J Surg, 180, 13-7.

Cheung R (2013). Racial and social economic factors impact on the cause specific survival of pancreatic cancer: a SEER survey. Asian Pac J Cancer Prev, 14, 159-63.

Compton CC, ed (2003). Reporting on cancer specimens. case summaries and background documentation 2003 edition, northfield, IL, College Am Pathol.

de Castro SM, van Heek NT, Kuhlmann KF, et al (2004). Surgical management of neoplasms of the ampulla of Vater: local resection or pancreaticoduodenectomy and prognostic features for survival. Surgery, 136, 994-1002.

Foroughi F, Mohsenifar Z, Ahmadvand A, et al (2012). Pathologic findings of whipple pancreaticoduodenectomy: a 5-year review on 51 cases at Taleghani general hospital. Gastrointerol Hepatol bed Bench, 5, 179-82.

Gudjonsson B (1987). Cancer of the pancreas. 50 years of surgery. Cancer, 60, 2284-303.

Hadizadeh M, Padashi M, Mohammad Alizadeh AH, Zali MR (2014). Clinical, laboratory biomarkers and imaging findings of pancreatic adenocarcinoma in Iran. Asian Pac J Cancer Prev, 15, 4349-52.

Kang HJ, Eo SH, Kim SC, et al (2013). Increased number of metastatic lymph nodes in adenocarcinoma of the ampulla of Vater as a prognostic factor: a proposal of new nodal classification. Surgery, 155, 74-84.

Kavanagh DO, O' Riain C, Ridgway PF, et al (2008). Radical pancreaticoduodenectomy for benign disease. Sci World J, 22, 1156-67.

Kayahara M, Ohta T (2010). Gross appearance of the ampullary tumor predicts lymph node metastases and outcome. Dig Surg, 27, 127-31.

Lazaryan A, Almhanna K, Elson P, et al (2008). Factors associated with tumor recurrence and 5-year postoperative survival in ampullary carcinoma. cleveland clinic experience. J Clin Oncol, 26, 155-75.

Longmire WP Jr, Traverso LW (1981). The Whipple procedure and other standard operative approaches to pancreatic cancer. 
Cancer, 47, 1706-11.

Luke C, Price T, Karapetis C, Singhal N, Roder D (2009). Pancreatic cancer epidemiology and survival in an australian population. Asian Pac J Cancer Prev, 10, 369-74.

Martin FM, Rossi RL, Dorrucci V, et al (1990). Clinical and pathologic correlations in patients with periampully tumors. Arch Surg, 125, 723-6.

Morris-stiff G, Alabraba E, Tan TM, et al (2009). Assessment of survival advantage in ampullary carcinoma in relation to tumor biology and morphology. Eur J Surg Oncol, 35, 746-50.

Mu DQ, Peng SY, Wang GF (2004). Risk factors influencing recurrence following resection of pancreatic head cancer. World J Gastroenterol, 10, 906-9.

Nix GA, Dubbelman C, Wilson JH, et al (1991). Prognostic implications of tumor diameter in carcinoma of the head of the pancreas. Cancer, 67, 529-35.

Qureshi A, Hassan U, Azam M (2011). Morphology, TNM staging and survival with pancreaticoduodenectomy specimens received at shaukat khanum memorial cancer hospital and research center, Pakistan. Asian Pac J Cancer Prev, 12, 953-6.

Rosai J ed (2004). Guidelines for handling of most common and important surgical specimens. rosai and ackerman's surgical pathology. $9^{\text {th }}$ edition, Mosby, St Louis, Missouri.

Sessa F, Furlan D, Zampatti C, et al (2007). Prognostic factors for ampullary adenocarcinomas: tumor stage, tumor histology, tumor location, immunohistochemistry and microsatellite instability. Virchows Arch, 451, 649-57.

Shrikhande SV, Barreto SG, Somashekar BA, et al (2013). Evoluation of pancreatoduodenectomy in a tertiary cancer center in India: Improved results from service recognition. Pancreaticol, 13, 63-71.

Sohn TA, Campbell KA, Pitt HA, et al (2000). Quality of life and long-term survival after surgery for chronic pancreatitis. J Gastrointest Surg, 4, 355-64.

Sohn TA, Yeo CJ, Cameros JL, et al (2000). Resected adenocarcinoma of the pancreas-616 patients: results, outcomes, and prognostic indicators. J Gastrointest Surg, 4, 567-79.

Tepper J, Nardi G, Sutt H (1976). Carcinoma of the pancreas. Review of MGH expression from 1963 to 1973. Analysis of surgical failure and implications for radiation therapy. Cancer, 37, 1519-24.

Thomas RM,Ahmad SA(2012). Current concepts in the surgical management of pancreatic cancer. Surg Oncol Clin N Am, 19, 335-58.

Unal OU, Oztop I, Assoc TK, et al (2014). Prognostic factors and adjuvant treatments for surgically treated cancers of the biliary tract: a multicentric study of the anatolian society of medical oncology (ASMO). Asian Pac J Cancer Prev, 15, 9687-92.

van Roest MH, Gouw AS, Peeters PM, et al (2008). Results of pancreaticoduodenectomy in patients with periampullary adenocarcinoma:perineural growth more important prognostic factor than tumor localization. Ann Surg, 248, 97-103.

Whipple AO, Parsons WB, Mullins CR (1935). Treatment of carcinoma of the ampulla of Vater. Ann Surg, 102, 763-79.

Willett CG, Warshaw AL, Convery K, et al (1993). Patterns of failure after pancreaticoduodenectomy for ampullary carcinoma. Surg Gynecol Obstet, 176, 33-8.

Yamaguchi K, Enjoji M (1987). Carcinoma of the ampulla of vater. A clinicopathologic study and pathologic staging of 109 cases of carcinoma and 5 cases of adenoma. Cancer, 59, 506-15.

Yeo CJ, Cameron JL, Sohn TA, et al (1997). Six hundred fifty consective pancreaticoduodenectomies in the 1990s: pathology, complications and outcomes. Ann Surg, 226, 248-57.

Zahir ST, Arjmand A, Kargar S, Neishaboury M (2013). Incidence and trends of malignant and benign pancreatic lesions in Yazd, Iran between 2001 and 2011. Asian Pac J Cancer Prev, 14, 2631-35. 